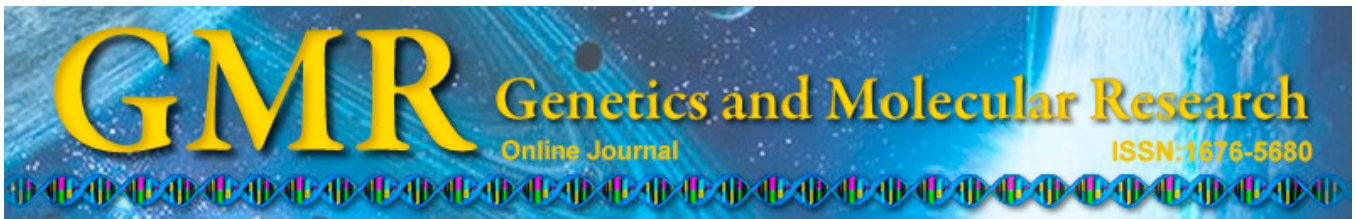

\title{
Correlation between polymorphism of platelet alloantigen genes $H P A-1-5$ and type 2 diabetes complication by carotid atherosclerosis in a Chinese population
}

\author{
Y.H. Zhang ${ }^{1}$, S.F. Xu' ${ }^{2}$, J. Zheng ${ }^{3}$, H.S. Hong ${ }^{1}$ and L.M. Fan ${ }^{1}$ \\ ${ }^{1}$ Emergency Department, Affiliated Hospital of Guiyang Medical College, \\ Guiyang, Guizhou, China \\ ${ }^{2}$ Intensive Care Unit, Wenzhou People's Hospital, Wenzhou, Zhejiang, China \\ ${ }^{3}$ Endocrinology Department, Affiliated Hospital of Guiyang Medical College, \\ Guiyang, Guizhou, China \\ Corresponding author: L.M. Fan \\ E-mail: Fanliangmin_flm@163.com \\ Genet. Mol. Res. 14 (2): 4607-4615 (2015) \\ Received July 16, 2014 \\ Accepted November 4, 2014 \\ Published May 4, 2015 \\ DOI http://dx.doi.org/10.4238/2015.May.4.19
}

\begin{abstract}
We investigated the association between the polymorphism of human platelet alloantigen genes HPA-1-HPA-5 and the complication of type 2 diabetes mellitus (T2DM) by carotid atherosclerosis (CA) among Han people in Guiyang District, China. Ninety-nine T2DM patients were selected from the Affiliated Hospital of Guiyang Medical College and divided into a $\mathrm{CA}(+)$ group and a CA(-) group. A control group comprised 100 healthy people from the medical examination center of the same hospital. Genomic DNA from all the subjects was isolated by phenol-chloroform extraction and target genes were amplified using sequence-specific primer-polymerase chain reaction, followed by gene type detection of $H P A$. There were significant differences in allele and genotype frequencies of $H P A-1,-2,-3$, and -5 among the three groups $[\mathrm{CA}(+), \mathrm{CA}(-)$, and the control group] $(\mathrm{P}<$
\end{abstract}


$0.05)$, and significant differences in allele and genotype frequencies of HPA-1, -2 , and -3 between groups $\mathrm{CA}(+)$ and $\mathrm{CA}(-)$ and the control group $(\mathrm{P}<0.05)$. Moreover, there was a significant difference in allele and genotype frequencies of HPA-5 between the $\mathrm{CA}(+)$ and $\mathrm{CA}(-)$ groups $(\mathrm{P}<0.05)$. Logistic regression analysis showed that risk factors for T2DM patients developing a CA complication were age, duration of diabetes, high blood pressure, smoking, overweight, abnormal blood lipid levels, and polymorphism of $H P A-5$. There may be a correlation between T2DM and polymorphism of HPA-1-3. Polymorphism of HPA5 is probably a risk factor for CA complicating T2DM.

Key words: Human platelet alloantigen; Gene polymorphism; Type 2 diabetes mellitus; Carotid atherosclerosis

\section{INTRODUCTION}

Diabetes is the third most common of all non-communicable diseases worldwide, while cardiovascular diseases caused by atherosclerosis are the main cause of death and disability among patients with type 2 diabetes mellitus (T2DM) (Cheng, 2009). As research into cardiovascular diseases has progressed, it has become apparent that human platelet alloantigen (HPA) is one of the influential factors in the initiation and progression of atherothrombosis. Polymorphism of the HPA genes brings about an effect on platelet function, mainly by affecting expression of platelet membrane proteins. Polymorphism of these genes can change glycoproteins, thus altering the antigenicity of platelet membranes, leading to dysregulation of HPA structure and expression levels, which in turn results in platelet activation, adhesion, and aggregation, one of the most important pathologies of atherosclerosis. In this study, we performed sequence-specific primer-polymerase chain reaction (SSP-PCR) to simultaneously amplify HPA-1-5 allele systems under the same amplification conditions (Shehata et al., 2011), so as to investigate the correlation between gene polymorphisms of HPA-1-5 and T2DM complication by carotid atherosclerosis (CA).

\section{MATERIAL AND METHODS}

\section{Subjects}

\section{T2DM group}

Ninety-nine in-hospital patients from the Affiliated Hospital of Guiyang Medical College were randomly selected. Inclusion criteria were in accordance with the World Health Organization T2DM diagnosis standard of 1999, and all patients were without acute complications or acute cardiovascular cerebrovascular disease. All patients were unrelated Han individuals from Guiyang District. Subjects were divided into two subsets according to whether or not they had CA. Fifty-nine patients with CA, 35 males and 24 females, with an average age of $63.84 \pm 11.06$ years, were put into the $\mathrm{CA}(+)$ group; while 43 patients without $\mathrm{CA}$, consisting of 23 males and 20 females, with an average age of $62.91 \pm 9.42$ years, were assigned to the $\mathrm{CA}(-)$ group. 


\section{Control group}

The control group comprised 100 healthy individuals (45 males and 55 females, with an average age of $62.97 \pm 11.32$ years) from the same hospital's medical examination center, who were also unrelated Han people from Guiyang District.

\section{Methods}

\section{Data collection and diagnosis criteria}

Age, gender, history of present illness, diagnosis, blood pressure, waistline, body height, body weight, and body mass index (BMI) of all the subjects were collected.

Diagnosis of CA was carried out by performing carotid ultrasound (Philips IU-22 color Doppler, $5000 \mathrm{HZ}$ ) on all the subjects. A complication of CA was diagnosed when carotid intima-media thickness $\geq 1.1 \mathrm{~mm}$, with focal protrusion of the wall into the lumen, according to the Joint Statement of the American Association of Ultrasound in 2004 (Touboul et al., 2007).

For waistline measurements, upright subjects were measured twice around the midpoint of the lowest point of the ribcage and the iliac spine edge to an accuracy of $1 \mathrm{~cm}$, and the average was taken as the waistline measurement. For BMI, subjects fasted following defecation and took an upright position on the scales without a coat or shoes and with their eyes pointed straight ahead; the weight in kilograms upon numerical stability was taken, accurate to $0.5 \mathrm{~kg}$ of body weight, and the BMI was calculated from weight $(\mathrm{kg}) /$ height $\left(\mathrm{m}^{2}\right)$.

Determination of hypertension was made in accordance with the 2010 Chinese Hypertension Prevention Guide: systolic blood pressure $\geq 140 \mathrm{mmHg}(1 \mathrm{mmHg}=0.133 \mathrm{kPa})$ and $/$ or diastolic blood pressure $\geq 90 \mathrm{mmHg}$, or if subjects were receiving antihypertensive therapy.

According to the World Health Organization, smokers were identified as smoking more than an average of 1 cigarette per day for more than 3 months.

Lipid abnormality, abdominal obesity, and overweight status were determined based on the criteria of the Chinese Adult Dyslipidemia Prevention Guide Joint Committee (2007). Lipid abnormality was assessed based on the following criteria: triglycerides $\geq 1.70 \mathrm{mM}$; total cholesterol $\geq 5.18 \mathrm{mM}$; high-density lipoprotein cholesterol $<1.04 \mathrm{mM}$. Abdominal obesity was determined based on a waist circumference greater than $90 \mathrm{~cm}$ for males and $80 \mathrm{~cm}$ for females. A subject was confirmed as overweight if their BMI $\geq 24.0 \mathrm{~kg} / \mathrm{m}^{2}$.

\section{Collection and analysis of clinical samples}

All patients with diabetes fasted overnight for more than $8 \mathrm{~h}$ and the following morning $3 \mathrm{~mL}$ venous blood was taken to determine blood glucose, blood lipids, and glycosylated hemoglobin.

Fasting plasma glucose and blood lipids were measured with a Beckman Automatic Biochemical Analyzer (Beckman Coulter International S.A., Brea, CA, USA), using the hexokinase method. Glycosylated hemoglobin was analyzed with a Byer DCA2000 Analyser for hemoglobin A1c and microalbumin (Byer AGl, Hamburger, Germany) system using cation exchange chromatography. 


\section{DNA extraction}

A 2-mL blood sample from each subject was collected using ethylenediaminetetraacetic acid K2 as an anticoagulant. Blood samples were centrifuged at $4000 \mathrm{rpm}$ for $10 \mathrm{~min}$ to stratify blood serum, erythrocytes, and leukocytes. The leukocyte layer of each sample was collected for storage and DNA extraction.

The genomic DNA of all subjects was isolated by phenol-chloroform extraction and an ultraviolet spectrophotometer was used to measure DNA concentration and purity. The $\mathrm{A}_{260} / \mathrm{A}_{280}$ ratio was approximately 1.7 , indicating high purity of DNA that was fit for storage and further study (an $\mathrm{A}_{260} / \mathrm{A}_{280}$ ratio of 1.6-1.8 usually means that the sample of DNA contains minimal impurities). Target genes were amplified using SSP-PCR, followed by gene type detection of HPA.

\section{Statistical analysis}

Statistical analysis was conducted using the SPSS17.0 software (SPSS Inc., Chicago, IL, USA). We took $\alpha=0.05$ as a significant level to test for Hardy-Weinberg equilibrium (Liu and $\mathrm{Hu}, 2010)$. Genotype, gene, and allele frequencies were calculated using the frequency counting method. For measurement data, we used the Student $t$-test to compare groups; for count data we used the chi-square $\left(\chi^{2}\right)$ test to compare between the two groups; risk factors for T2DM-complicating CA were analyzed by logistic regression analysis.

\section{RESULTS}

\section{Analysis of electrophoresis results}

The presence of the internal marker gene, which is 429 bp for HPA-1-5, in each well indicated successful amplification. Genotype was identified by the presence of specific bands at certain positions. For instance, when a specific band appeared at the position for gene a but no band appeared at gene b's position, an aa genotype was confirmed. Likewise, an ab genotype was identified when specific bands appeared at positions a and b. Finally, when only one specific band appeared at the position for gene $b$, and no such band appeared at the a position, a bb genotype was confirmed. The results of the electrophoresis are shown in Figure 1. Sizes of each specific gene fragment were: HPA-3a, 267 bp; HPA-3b, 269 bp; HPA-1 (a \& b), 196 bp; HPA-2 (a \& b), 241 bp; HPA-4 (a \& b), 252 bp; and HPA-5 (a \& b), 246 bp. For allele frequency and genotypes of all specific gene fragments, see Table 1.

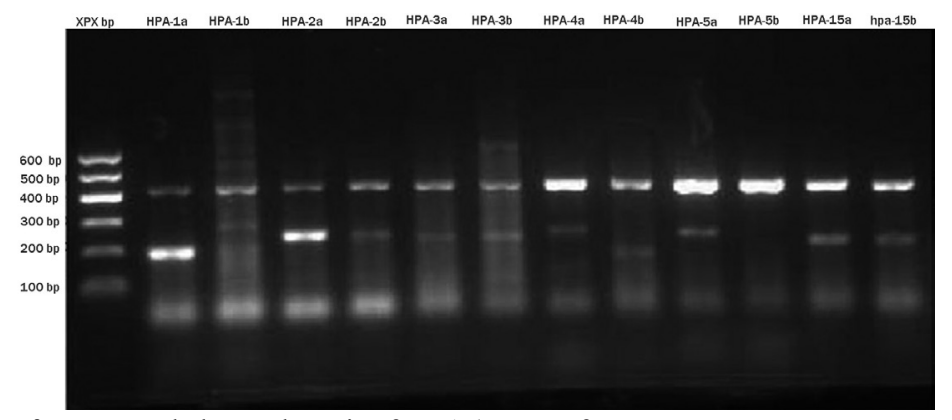

Figure 1. Results of agarose gel electrophoresis of HPA-1-5 gene fragments. 


\begin{tabular}{|c|c|c|c|c|c|c|c|c|c|}
\hline \multirow[t]{2}{*}{ Gene } & \multicolumn{2}{|c|}{ Gene frequency } & \multirow[t]{2}{*}{$\chi^{2}$} & \multirow[t]{2}{*}{$\mathrm{P}$} & \multicolumn{3}{|c|}{ Genotype } & \multirow[t]{2}{*}{$\chi^{2}$} & \multirow[t]{2}{*}{$P$} \\
\hline & $\mathrm{a}$ & $\mathrm{b}$ & & & aa & $\mathrm{ab}$ & $\mathrm{bb}$ & & \\
\hline \multicolumn{10}{|l|}{$\overline{H P A-1}$} \\
\hline Control & 0.905 & 0.095 & $19.740^{\mathbf{\Lambda}}$ & $<0.05$ & 81 & 19 & 0 & $20.775^{\wedge}$ & $<0.05$ \\
\hline $\mathrm{CA}(+)$ & 1.0 & 0 & $19.703^{\wedge \Lambda}$ & $<0.05$ & 56 & 0 & 0 & $20.795^{\Delta \Lambda}$ & $<0.05$ \\
\hline $\mathrm{CA}(-)$ & 1.0 & 0 & 0 & 1 & 43 & 0 & 0 & 0 & 1 \\
\hline \multicolumn{10}{|l|}{$H P A-2$} \\
\hline Control & 0.6450 & 0.3550 & $27.172^{\wedge}$ & $<0.05$ & 30 & 69 & 1 & $40.315^{\wedge}$ & $<0.05$ \\
\hline $\mathrm{CA}(+)$ & 0.8661 & 0.1339 & $18.750^{\wedge \Lambda}$ & $<0.05$ & 41 & 15 & 0 & $40.164^{\wedge \Lambda}$ & $<0.05$ \\
\hline $\mathrm{CA}(-)$ & 0.8837 & 0.1163 & $2.832^{\Delta \Delta \Delta}$ & $>0.05$ & 33 & 10 & 0 & $0.161^{\wedge \wedge \Delta}$ & $>0.05$ \\
\hline \multicolumn{10}{|l|}{$H P A-3$} \\
\hline Control & 0.5950 & 0.4050 & $37.969^{\wedge}$ & $<0.05$ & 26 & 67 & 7 & $87.783^{\wedge}$ & $<0.05$ \\
\hline $\mathrm{CA}(+)$ & 0.9196 & 0.0804 & $31.188^{\mathbf{\Lambda}}$ & $<0.05$ & 51 & 1 & 4 & $86.226^{\boldsymbol{\Lambda}}$ & $<0.05$ \\
\hline $\mathrm{CA}(-)$ & 0.9418 & 0.0582 & $0.364^{\Delta \Lambda \Delta}$ & $>0.05$ & 38 & 5 & 0 & $0.195^{\Delta \Lambda \Delta}$ & $>0.05$ \\
\hline \multicolumn{10}{|l|}{$H P A-4$} \\
\hline Control & 1.00 & 0 & 0 & 1 & 100 & 0 & 0 & 0 & 1 \\
\hline $\mathrm{CA}(+)$ & 1.00 & 0 & 0 & 1 & 56 & 0 & 0 & 0 & 1 \\
\hline $\mathrm{CA}(-)$ & 1.00 & 0 & 0 & 1 & 43 & 0 & 0 & 0 & 1 \\
\hline \multicolumn{10}{|l|}{$H P A-5$} \\
\hline Control & 0.9650 & 0.0350 & $9.870^{\wedge}$ & $<0.05$ & 93 & 7 & 0 & $7.903^{\wedge}$ & $<0.05$ \\
\hline $\mathrm{CA}(+)$ & 0.9107 & 0.0893 & $0.974^{\wedge \Lambda}$ & $>0.05$ & 48 & 6 & 2 & $1.970^{\Delta \Lambda}$ & $>0.05$ \\
\hline $\mathrm{CA}(-)$ & 0.9883 & 0.0117 & $5.563^{\wedge \Delta \Delta}$ & $<0.05$ & 42 & 1 & 0 & $4.386^{\boldsymbol{\Lambda} \Lambda \boldsymbol{\Lambda}}$ & $<0.05$ \\
\hline
\end{tabular}

${ }^{\boldsymbol{\Delta}}$ Comparison among $\mathrm{CA}(+), \mathrm{CA}(-)$, and control; ${ }^{\boldsymbol{\Lambda} \boldsymbol{\Delta}}$ comparison between T2DM groups [CA(+) and $\left.\mathrm{CA}(-)\right]$ and control group; ${ }^{\boldsymbol{\Delta} \Delta}$ comparison between $\mathrm{CA}(+)$ and $\mathrm{CA}(-)$.

\section{Frequencies of gene polymorphism in allele system and distribution of genotypes}

In the control group, allele frequencies of $H P A-1,-2,-3$, and -5 showed a polymorphic distribution, while $H P A-4$ showed a singlet distribution (only $H P A-4$ a was detected, with no $H P A-4 \mathrm{~b}$ allele found).

With all subjects with $H P A-4$ being aa homozygotes, $H P A-1$ and -5 showed a majority frequency of aa homozygotes, while bb homozygotes appeared in $H P A-2$ and 3 but not in the other HPA genes. Furthermore, a heterozygous type ab appeared in $H P A-1,-2,-3$, and -5 , in which $H P A-2$ showed the highest heterozygosity frequency and $H P A-5$ the lowest (see Table 1).

In the $\mathrm{CA}(+)$ group, allele frequencies of $H P A-2,-3$, and -5 showed a polymorphic distribution, while $H P A-1$ and -4 showed a singlet distribution (only HPA-la and $H P A-4$ a were detected, with no HPA- $1 \mathrm{~b}$ or HPA- $4 \mathrm{~b}$ alleles found). HPA-1 and -4 were entirely aa homozygotes, HPA$2,-3$, and -5 showed a majority frequency of aa homozygotes, while bb homozygotes appeared in HPA-3 and -5 but not in other HPA genes. Moreover, a heterozygous type ab appeared in HPA-2, -3 , and -5 , in which $H P A-2$ showed the highest heterozygosity and $H P A-5$ the lowest (see Table 1 ).

In the CA(-) group, allele frequencies of $H P A-2,-3$ and -5 showed a polymorphic distribution, while $H P A-1$ and 4 showed a singlet distribution (only HPA-1 a and $H P A-4$ a were detected, with no HPA- $1 \mathrm{~b}$ or HPA-4b alleles found). HPA-1 and -4 were entirely aa homozygotes, and $H P A-2,-3$, and -5 showed a majority frequency of aa homozygotes. Furthermore, a heterozygous type ab appeared in $H P A-2,-3$ and -5 , in which $H P A-2$ showed the highest heterozygosity (Table 1).

The Hardy-Weinberg goodness of fit test was applied to compare measured and predicted values of genotype frequencies among the $\mathrm{CA}(+), \mathrm{CA}(-)$, and control groups. Chi-square values were calculated with 2 degrees of freedom, and the $\mathrm{P}$ values were greater than 0.05 , implying a compliance with the Hardy-Weinberg equilibrium law of population genetics (Table 2). 
Table 2. Hardy-Weinberg test of genotype distributions among groups.

\begin{tabular}{|c|c|c|c|c|c|c|c|c|c|c|c|c|}
\hline \multirow[b]{2}{*}{ Gene } & \multicolumn{4}{|c|}{ Control } & \multicolumn{4}{|c|}{$\mathrm{CA}(+)$} & \multicolumn{4}{|c|}{$\mathrm{CA}(-)$} \\
\hline & $\begin{array}{c}\text { Measured } \\
\text { values }\end{array}$ & $\begin{array}{c}\text { Predicted } \\
\text { values }\end{array}$ & $\chi^{2}$ & $P$ & $\begin{array}{c}\text { Measured } \\
\text { values }\end{array}$ & $\begin{array}{c}\text { Predicted } \\
\text { values }\end{array}$ & $\chi^{2}$ & $\mathrm{P}$ & $\begin{array}{l}\text { Measured } \\
\text { values }\end{array}$ & $\begin{array}{l}\text { Predicted } \\
\text { values }\end{array}$ & $\chi^{2}$ & $\mathrm{P}$ \\
\hline 1 aa & 81 & 81.90 & 1.104 & $>0.05$ & 56 & 56 & 0 & 1 & 43 & 43 & 0 & 1 \\
\hline $1 \mathrm{ab}$ & 19 & 17.19 & & & 0 & 0 & & & 0 & 0 & & \\
\hline $1 b b$ & 0 & 0.902 & & & 0 & 0 & & & 0 & 0 & & \\
\hline $2 \mathrm{aa}$ & 30 & 40.90 & 2.824 & $>0.05$ & 41 & 42.00 & 0.047 & $>0.05$ & 33 & 33.58 & 0.06 & $>0.05$ \\
\hline $2 a b$ & 69 & 45.79 & & & 15 & 11.02 & & & 10 & 9.42 & & \\
\hline $2 b b$ & 1 & 1.2 & & & 0 & 0.24 & & & 0 & 0.04 & & \\
\hline $3 \mathrm{aa}$ & 26 & 35.40 & 1.191 & $>0.05$ & 51 & 47.36 & 2.294 & $>0.05$ & 38 & 38.14 & 0.07 & $>0.05$ \\
\hline $3 a b$ & 67 & 48.19 & & & 1 & 3.18 & & & 5 & 4.84 & & \\
\hline $3 b b$ & 7 & 13.5 & & & 4 & 1.35 & & & 0 & 0.01 & & \\
\hline $4 \mathrm{aa}$ & 100 & 100 & 0 & 1 & 10 & 100 & 0 & 1 & 43 & 43 & 0 & 1 \\
\hline $4 \mathrm{ab}$ & 0 & 0 & & & 0 & 0 & & & 0 & 0 & & \\
\hline $4 \mathrm{bb}$ & 0 & 0 & & & 0 & 0 & & & 0 & 0 & & \\
\hline 5 aа & 93 & 93.12 & 0.620 & $>0.05$ & 48 & 46.44 & 0.265 & $>0.05$ & 42 & 42.01 & 0.01 & $>0.05$ \\
\hline $5 \mathrm{ab}$ & 7 & 7.97 & & & 6 & 7.54 & & & 1 & 0.99 & & \\
\hline $5 \mathrm{bb}$ & 0 & 0.64 & & & 2 & 1.78 & & & 0 & 0.15 & & \\
\hline
\end{tabular}

\section{Comparison of gene and genotype frequencies of the $H P A$ allele system among groups}

The gene frequencies among the $\mathrm{CA}(+), \mathrm{CA}(-)$, and control groups are shown in Table 1. There were significant differences in gene frequencies of HPA-1, -2, -3, and -5 among the $\mathrm{CA}(+), \mathrm{CA}(-)$, and control groups $\left(\chi^{2}=19.740, \chi^{2}=27.172, \chi^{2}=37.969\right.$, and $\chi^{2}=9.870$, respectively; $\mathrm{P}<0.05$ ), while there was no significant difference in the $H P A-4$ frequency among the three groups. Meanwhile, there were significant differences in genotypes of $H P A-1,-2,-3$, and -5 among the $\mathrm{CA}(+), \mathrm{CA}(-)$, and control groups $\left(\chi^{2}=20.775, \chi^{2}=40.315, \chi^{2}=87.783\right.$, and $\chi^{2}=$ 7.903, respectively; $\mathrm{P}<0.05$ ), and once again no difference in HPA-4 genotype was observed.

There were also significant differences in gene frequencies of $H P A-1,-2$, and -3 between the T2DM groups and the control group $\left(\chi^{2}=19.703, \chi^{2}=18.750\right.$, and $\chi^{2}=31.188$, respectively; $\mathrm{P}<0.05$ ), while there was no significant difference in frequency of HPA-4 and -5 between the two groups. Meanwhile, there were significant differences in genotypes of $H P A-1$, -2 , and -3 between the T2DM groups and the control group, but no such difference of HPA-4 and -5 genotypes was observed.

For comparison of gene frequencies between $\mathrm{CA}(+)$ and $\mathrm{CA}(-)$, see Table 2 . There were significant difference of frequencies and genotype of HPA-5 between the two groups $\left(\chi^{2}\right.$ $=5.563 ; \mathrm{P}<0.05$ for gene and $\chi^{2}=4.386 ; \mathrm{P}<0.05$ for genotype), while no significant difference of $H P A-1,-2,-3$, and -4 was observed.

\section{Comparison of general characteristics between the $\mathrm{CA}(+)$ and $\mathrm{CA}(-)$ groups}

Table 3 shows that average age, duration of diabetes, glycated hemoglobin, triglycerides, cholesterol, high-density lipoprotein cholesterol, low-density lipoprotein cholesterol, $\mathrm{BMI}$, and waist circumference of $\mathrm{CA}(+)$ patients were higher than those of $\mathrm{CA}(-)$ patients, but the differences were not statistically significant $(\mathrm{P}>0.05)$. Moreover, the $\mathrm{CA}(+)$ group had higher percentages of smokers, those with hypertension, those who were overweight, and those with abdominal obesity compared with the $\mathrm{CA}(-)$ group, although again the differences were not statistically significant $(\mathrm{P}>0.05)$. 
Table 3. Comparison of general information between $\mathrm{CA}(+)$ and $\mathrm{CA}(-)$ groups.

\begin{tabular}{|c|c|c|c|c|}
\hline Group information & $\mathrm{CA}(+)[$ means $\pm \mathrm{SD}$ or $\mathrm{N}(\%)]$ & $\mathrm{CA}(-)[$ means $\pm \mathrm{SD}$ or $\mathrm{N}(\%)]$ & Statistics $\left(t\right.$ or $\left.\chi^{2}\right)$ & $P$ value \\
\hline Age (years) & $63.84 \pm 11.06$ & $62.91 \pm 9.42$ & $t=1.767$ & $\mathrm{P}>0.05$ \\
\hline Number of cases $(\mathrm{M} / \mathrm{F})$ & $56(35 / 24)$ & $43(23 / 20)$ & $\chi^{2}=0.534$ & $\mathrm{P}>0.05$ \\
\hline Duration of DM (years) & $7.84 \pm 5.73$ & $5.96 \pm 5.82$ & $t=1.603$ & $P>0.05$ \\
\hline $\mathrm{HbA} 1 \mathrm{C}(\%)$ & $8.32 \pm 2.24$ & $8.23 \pm 2.13$ & $t=1.056$ & $\mathrm{P}>0.05$ \\
\hline $\mathrm{TG}(\mathrm{mM})$ & $2.369 \pm 2.19$ & $2.363 \pm 1.66$ & $t=0.007$ & $\mathrm{P}>0.05$ \\
\hline CHOL (mM) & $4.71 \pm 1.193$ & $4.53 \pm 1.096$ & $t=0.134$ & $\mathrm{P}>0.05$ \\
\hline $\operatorname{LDLC}(\mathrm{mM})$ & $2.81 \pm 1.055$ & $2.73 \pm 1.013$ & $t=0.129$ & $\mathrm{P}>0.05$ \\
\hline HDLC (mM) & $1.012 \pm 0.229$ & $1.041 \pm 0.396$ & $t=0.428$ & $\mathrm{P}>0.05$ \\
\hline BMI $\left(\mathrm{kg} / \mathrm{m}^{2}\right)$ & $24.66 \pm 4.083$ & $23.32 \pm 3.682$ & $t=1.691$ & $\mathrm{P}>0.05$ \\
\hline Waist circumference $(\mathrm{cm})$ & $88.43 \pm 11.41$ & $84.16 \pm 10.83$ & $t=1.884$ & $\mathrm{P}>0.05$ \\
\hline Number smoking & $35(62.50 \%)$ & $19(32.5 \%)$ & $\chi^{2}=1.984$ & $\mathrm{P}>0.05$ \\
\hline Number with hypertension & $31(55.35 \%)$ & $22(51.16 \%)$ & $\chi^{2}=0.172$ & $\mathrm{P}>0.05$ \\
\hline Number of overweight & $27(48.21 \%)$ & $15(34.88 \%)$ & $\chi^{2}=1.770$ & $\mathrm{P}>0.05$ \\
\hline Number with abdominal obesity & $30(53.57 \%)$ & $20(46.51 \%)$ & $\chi^{2}=0.485$ & $\mathrm{P}>0.05$ \\
\hline
\end{tabular}

$\mathrm{DM}=$ diabetes mellitus; HbA1C $=$ glycated hemoglobin; $\mathrm{TG}=$ triglycerides; $\mathrm{CHOL}=$ cholesterol; $\mathrm{LDLC}=$ lowdensity lipoprotein cholesterol; HDLC = high-density lipoprotein cholesterol; BMI = body mass index.

\section{Risk factors for patients with T2DM developing CA}

For all the T2DM patients, complication by CA was taken as a dependent variable, and old age, duration of diabetes, hypertension, smoking, being overweight, lipid abnormality, abdominal obesity, and $H P A-5$ polymorphism were taken as independent variables. Logistic regression analysis showed that old age [odds ratio $(\mathrm{OR})=1.089,95 \%$ confidence interval $(95 \% \mathrm{CI})=0.255-1.652]$, longer duration of diabetes $(\mathrm{OR}=1.028,95 \% \mathrm{CI}=0.946-1.135)$, hypertension $(\mathrm{OR}=1.008,95 \% \mathrm{CI}=0.930-1.101)$, smoking $(\mathrm{OR}=1.100,95 \% \mathrm{CI}=1.024-$ $1.128)$, being overweight $(\mathrm{OR}=1.023,95 \% \mathrm{CI}=0.886-1.295)$, lipid abnormality $(\mathrm{OR}=1.433$, $95 \% \mathrm{CI}=0.759-1.375)$, and polymorphism of $H P A-5(\mathrm{OR}=1.142,95 \% \mathrm{CI}=0.102-1.209)$ are risk factors for T2DM patients developing CA, but abdominal obesity is not (Table 4).

Table 4. Logistic regression analysis of possible risk factors for T2DM-complicating CA.
\begin{tabular}{lccc}
\hline Independent variables & Wald $\left(\chi^{2}\right)$ & Sig (P value $)$ & OR $(95 \%$ CI $)$ \\
\hline Old age (years) & 23.674 & 0.000 & $1.089(0.255-1.652)$ \\
Longer DM duration (years) & 23.163 & 0.000 & $1.028(0.946-1.135)$ \\
Hypertension & 19.477 & 0.003 & $1.008(0.930-1.101)$ \\
Smoking & 8.194 & 0.040 & $1.100(1.024-1.128)$ \\
Overweight & 29.194 & 0.000 & $1.023(0.886-1.295)$ \\
Lipid abnormality & 60.417 & 0.000 & $1.433(0.759-1.375)$ \\
Abdominal obesity & 0.677 & 0.411 & $1.015(0.949-1.085)$ \\
HPA-5 polymorphism & 28.744 & 0.030 & $1.142(0.102-1.209)$ \\
\hline
\end{tabular}

$\mathrm{DM}=$ diabetes mellitus; $\mathrm{OD}=$ odds ratio; $\mathrm{CI}=$ confidence interval.

\section{DISCUSSION}

As molecular biology progresses, it has become apparent that atherosclerosis is a genetic disease affected by multiple genes, and interventions targeting the relevant genes would probably lead to its reduction and/or elimination, thereby saving medical costs. Therefore, a search for the target genes has begun.

The relevance of the polymorphism of the platelet gene PlA2 (now known as HPA-1) 
to acute coronary syndrome was first reported in 1996 by Weiss et al. Correlation between the two has been one of the central issues ever since. This study focused on the gene distribution of HPA-1 among a $\mathrm{CA}(+)$ group (T2DM with $\mathrm{CA}$ ), a $\mathrm{CA}(-)$ group (T2DM without $\mathrm{CA})$, and a control group (healthy people), and the results showed that for HPA-1, only the aa genotype appeared in the $\mathrm{CA}(+)$ and $\mathrm{CA}(-)$ groups, while the heterozygous genotype ab appeared in the control group (15\%). This result indicates that a majority of aa homozygotes exists among Han people, which is in agreement with the results of Bennett et al. (2002) and Halle et al. (2005) that there is a low distribution of $H P A-1 \mathrm{~b}$ among Asian and East African populations. The significant difference of $H P A-1$ polymorphism between the T2DM groups and the control group suggests a significant correlation between $H P A-1$ polymorphism and diabetes $(\mathrm{P}<0.05)$, which does not match the results of Nomura et al. (2006). This divergence may be explained by gene expression differences caused by ethnic and geographical differences.

Highly polymorphic distribution of $H P A-2$ among populations is one of the main factors affecting platelet function. Abboud et al. (2010) found that the HPA-2 gene is not only an independent risk factor for coronary heart disease, but also correlates significantly with its severity. Nevertheless, Nomura et al. (2006) found no significant difference in HPA-2 between T2DM patients, with or without atherosclerosis, and healthy people. In this study, significant difference of HPA-2 genotype was observed between the T2DM groups $[\mathrm{CA}(+)$ and $\mathrm{CA}(-)$ groups] and the control group $(\mathrm{P}<0.05)$, suggesting a correlation between $H P A-2$ genotype and T2DM. Contradiction between this result and that of Nomura et al. (2006) may be caused by ethnic and geographical differences.

HPA-3 polymorphism (especially that of GP II $\mathrm{b}$ ) has been found to be closely related with, and probably is an independent risk factor of, coronary heart disease among Han people in Beijing and Hebei District (Xue et al., 2009). Nomura et al. (2006) found no significant difference in HPA-3 among T2DM patients, with or without atherosclerosis, and healthy people. Our study showed that, compared to the control group, there is a lower frequency of $H P A-3 \mathrm{~b}$, but a higher frequency of $H P A-3 \mathrm{a}$, and a much lower frequency of heterozygous genotype ab in the T2DM groups, suggesting correlation with T2DM $(\mathrm{P}<0.05)$.

For $H P A-5$, there are different allele frequencies among different ethnic groups, and polymorphism in position GP I a is what affects platelet function. In this study, we observed a higher frequency of HPA-5b (including ab and bb genotypes) in the $\mathrm{CA}(+)$ group, compared with the $\mathrm{CA}(-)$ group. This result suggests a significant correlation between HPA-5b and atherosclerosis in T2DM patients, which also contradicts the result of Nomura et al. (2006). This may also be caused by ethnic and geographical differences.

With regards to $H P A-4$, no significant differences were observed among the $\mathrm{CA}(+)$ group, the $\mathrm{CA}(-)$ group, and the control group $(\mathrm{P}>0.05)$. Only HPA-4a was detected in our study, which is consistent with relevant literature (Li et al., 2006).

General characteristics of T2DM patients were analyzed using logistic regression analysis, and old age, longer duration of diabetes, hypertension, smoking, being overweight, and lipid abnormality were identified as risk factors for T2DM patients developing CA. Apart from these conventional risk factors, our study is the first to demonstrate that gene polymorphism of HPA-5 are also found to be a possible risk factor for T2DM-complicating CA.

We investigated the correlation of HPA gene polymorphisms and diabetes-complicating CA, but only among Han people from Guiyang District. Considering ethnic and geographical difference of the HPA gene, differences in case selection criteria, statistical methodology, 
and bias of data processing, among other factors, our study is still limited and needs expansion to confirm these results.

\section{ACKNOWLEDGMENTS}

Research supported by a project fund from the Guiyang City Research Plan Project of Technology Bureau Scientific [\#2012 (24)].

\section{REFERENCES}

Abboud N, Ghazouani L, Ben-Hadj-Khalifa S, Anabi F, et al. (2010). Human platelet alloantigens HPA-1, HPA-2, and HPA-3 polymorphisms associated with extent of severe coronary artery disease. J. Thromb. Thrombolysis 29: 409-415.

Anonymous (2007). Chinese guidelines on prevention and treatment of dyslipidemia in adults. Zhonghua Xin Xue Guan Bing Za Zhi 35: 390-419.

Bennett JA, Palmer LJ, Musk AW and Erber WN (2002). Gene frequencies of human platelet antigens 1-5 in indigenous Australians in Western Australia. Transfus. Med. 12: 199-203.

Cheng H (2009). Diabetes. Internal Medicine. Seventh Edition. People's Medical Publishing House, 1-6.

Halle L, Bigot A, Mulen-Imandy G, M'Bayo K, et al. (2005). HPA Polymorphism in Sub-Saharan African Populations: Beninese, Cameroonians, Congolese, and Pygmies. Tissue Antigens 65: 295-298.

Li S, Wang CL and Xie YB (2006). Changsha region fixed blood platelet antigen gene polymorphisms and 1 5, and 15 system analysis. Zhongguo Shuxue Zazhi 19: 198-200.

Liu $\mathrm{H}$ and $\mathrm{Hu}$ YH (2010). In the study of genetic epidemiology H-W balance test. Zhongnan Daxue Xuebao 35: 90-92.

Nomura S, Shouzu A, Omoto S, Matsuzaki T, et al. (2006). Genetic analysis of HLA, NA and HPA typing in type 2 diabetes and ASO. Int. J. Immunogenet. 33: 117-122.

Shehata N, Denomme GA, Hannach B, Banning N, et al. (2011). Mass-scale high-throughput multiplex polymerase chain reaction for human platelet antigen single-nucleotide polymorphisms screening of apheresis platelet donors. Transfusion 51: 2028-2033.

Touboul PJ, Hennerici MG, Meairs S, Adams H, et al. (2007). Mannheim carotid intima-media thickness consensus (2004-2006). An update on behalf of the Advisory Board of the 3rd and 4th Watching the Risk Symposium, 13th and 15th European Stroke Conferences, Mannheim, Germany, 2004, and Brussels, Belgium, 2006. Cerebrovasc. Dis. 23: 75-80.

Weiss EJ, Bray PF, Tayback M, Schulman SP, et al. (1996). A polymorphism of a platelet glycoprotein receptor as an inherited risk factor for coronary thrombosis. N. Engl. J. Med. 334: 1090-1094.

Xue M, Chen KJ and Yin HJ (2009). Han platelet HPA-3 GP II b gene polymorphism and coronary heart disease (CHD) correlation studies. Zhongguo Bingli Shengli Zazhi 25: 1898-1902. 